Research Paper

\title{
APPLICATION OF MOBILE DUST MONITORING SYSTEM TO EVALUATE DUST CONCENTRATION IN SEVERAL STREETS OF HANOI CITY
}

\author{
Nguyen Anh Dung1, Le Van Quy², Le Ngoc Cau², Le Van Linh' ${ }^{2}$ Pham Thi Quynh²
}

\section{ARTICLE HISTORY}

Received: August 12, 2019 Accepted: September 15, 2019

Publish on: October 25, 2019

\section{ABSTRACT}

This study attempted to design an intelligent, portable device as hardware for dust measurement by IMHEN. The device is able to collect a specific dust level, the time and location of various measurements, and environment parameters such as temperature, relative humidity, atmosphere pressure, etc. The device's design used the programmable Arduino Mega 2560 board as the main processing unit. The device is small, portable, battery-operated which makes it to be suitable for mobile measurement of environment parameters. Additionally, the device has been applied to monitor dust concentration at different time scale in some main routes of Hanoi city. The analysis of monitoring results showed that there were differences of dust concentrations at off-peak hours among different routes. The total dust concentration (TSP) observed that some roads such as La Thanh, Lang Ha, surounding Road No.3, Tran Duy Hung, Nguyen Chi Thanh were higher 1.5 to 2 times than the permissible limit value according to QCVN 05:2013/BTNMT

Keywords: Mobile dust monitoring device, Dust pollution, Hanoi city.

$\triangle$ Le Van Quy

Corresponding author: 1vquy265@gmail.com ${ }^{1}$ Department of Science and Technology, MONRE

${ }^{2}$ Vietnam Institute of Meteorology Hydrology and Climate change

\section{Introduction}

In the present, the growing trend and air pollution were intensively tracked through the environment paramters to have a better monitoring solution. Instead of using big and static measuring stations, human developed the compact, multi-functional and intelligent device (Devarakonda, 2013; Mead et al., 2012; Yu et al., 2013). With the development of integrated circuits, one modern device can integrate many functions inside that is very nessessary .

In big cities, air pollution was more and more serious along with the significant increase of urbanization. The monitoring of air quality, especially the dust concentration in the air, was a essential requirement to improve the efficiency of environmental quality monitoring. The mobile dust monitoring device might assist in monitoring dust pollution in real time and space in cities. The main objective of this study was to design, install and integrate a set of compact, multifunctional and intelligent dust and meteorological element monitoring device.

The device was designed and assembled for mobile monitoring of dust, temperature, humidity, pressure and GPS navigation parameters. The data from the device was utilized to develop a current pollution map of the TSP dust concen- 
tration on some main streets of Hanoi City.

\section{Methodology}

2.1. The design and installation of mobile dust monitoring device

The mobile dust monitoring equipment is configured as follows: a sensor, timer, GPS receiver, LCD touch screen, central processor unit, GPS navigation, sensor of temperature and humidity, time reader, and memory card that are connected to the central processor unit through different interfaces. The central processor unit has a function to control the operation of these parts. When the device starts working, the sensors collect data on dust concentration and other meteorological parameters such as humidity, temperature, air pressure, coordinates and time; and record these parameters in memory cards.

The research team has summarized and designed based on a number of similar mobile monitoring methods implemented in other studies (Table 1). In this study, a dust monitoring device in the environment was concerned. The main requirements for the device are: 1) Collecting the dust level measurement from an external professional instrument device; 2) The location, time and other parameters (temperature, humidity, atmospheric pressure, etc) to associate with the dust measuring point; 3) The device should be portable and battery-operated; 4) It has a built-in LCD screen to display various parameters and the dust level itself; 5) It also has built-in memory storage to exchange the data.

Table 1. A number of mobile dust measurement methodologies in the world

\begin{tabular}{|c|c|c|c|c|}
\hline Author & $\begin{array}{c}\text { Means of } \\
\text { observation }\end{array}$ & Device & Parameter & Time \\
\hline Kaur et. al (2007) & Walk & $\begin{array}{l}\text { TSI P-Trak } 8525 \\
\text { A high-flow } \\
\text { personal sampler } \\
\text { (HFPS) }\end{array}$ & $\begin{array}{l}\text { Dust (superfine } \\
\text { particle counting) } \\
\text { PM }_{2.5}\end{array}$ & $1 \mathrm{~s}$ \\
\hline $\begin{array}{l}\text { Isakov et. al } \\
(2007)\end{array}$ & Minivan & $\begin{array}{l}\text { Mobility analyzer } \\
\text { TSI } 3071 \text { and } \\
\text { Particle counting } \\
\text { equipment TSI } \\
3010\end{array}$ & $\begin{array}{l}\text { Dust (superfine } \\
\text { particle) }\end{array}$ & $30 \mathrm{~s}$ \\
\hline Airparif (2009) & $\begin{array}{l}\text { Tricycle for } \\
\text { carrying goods }\end{array}$ & $\begin{array}{l}\text { P-Trak } \\
\text { Thermo Scientific } \\
42 \mathrm{i}\end{array}$ & $\begin{array}{l}\text { Dust (superfine } \\
\text { particle) } \\
\mathrm{NO} ; \mathrm{NO}_{2} ; \mathrm{NO}_{\mathrm{x}}\end{array}$ & $\begin{array}{l}1 \mathrm{~s} \\
60 \mathrm{~s}\end{array}$ \\
\hline $\begin{array}{l}\text { Wallace et. al } \\
\text { (2009) }\end{array}$ & Van & $\begin{array}{l}\text { Thermo Scientific } \\
42 \mathrm{i}\end{array}$ & $\mathrm{NO} ; \mathrm{NO}_{2} ; \mathrm{NO}_{\mathrm{x}}$ & $10 \mathrm{~s}$ \\
\hline $\begin{array}{l}\text { Dionisio et. al } \\
\text { (2010) }\end{array}$ & Walk & Dust-Trak 8520 & $\mathrm{PM}_{10} ; \mathrm{PM}_{2.5}$ & $60 \mathrm{~s}$ \\
\hline Vogel et. al (2011) & $\begin{array}{l}\text { Put in Backpacks } \\
\text { (walking or going } \\
\text { by bicycle) }\end{array}$ & $\begin{array}{l}\text { GRIMM OPC and } \\
\text { GRIMM Nano } \\
\text { check }\end{array}$ & $\begin{array}{l}\text { Dust (superfine } \\
\text { particle); } \mathrm{PM}_{10} \text {; } \\
\mathrm{PM}_{2.5} ; \mathrm{PM}_{1}\end{array}$ & $\begin{array}{c}\text { 60s for superfine } \\
\text { particle and } 6 \text { s for } \\
\text { dust }\end{array}$ \\
\hline Dons et. al (2011) & Put in Backpacks & AethLabs AE51 & $\mathrm{BC}$ & $300 \mathrm{~s}$ \\
\hline Adams et. al & Van & GRIMM 1.107 & $\mathrm{PM}_{2.5}$ & $1 \mathrm{~s}$ \\
\hline$(2012)$ & & Monitor Lab 8850 & $\mathrm{SO}_{2}$ & $1 \mathrm{~s}$ \\
\hline & & $\begin{array}{l}\text { Thermo Scientific } \\
48\end{array}$ & $\mathrm{CO}$ & $1 \mathrm{~s}$ \\
\hline
\end{tabular}

The general schematic of the device is presented on the Fig. 1.

On this schematic, there are following main functional blocks:

\section{(1) Dust sensor}

The dust measuring device (Haz-Dust HD 1100) was selected for this study. This is a modern dust equipment using the scattering imaging method so that it ensures high accuracy and reliability. Furthermore, the device also has external memory to store data (https://www.skcinc.com/catalog/). The specifications are described as below:Measuring range: $0.01-200 \mathrm{mg} / \mathrm{m}^{3}$ (1 to $20,000 \mu \mathrm{g} / \mathrm{m}^{3}$ ); Particle size: $0.01-120 \mu \mathrm{m}$; Accuracy: $\pm 0.02 \mathrm{mg} / \mathrm{m}^{3}$; Sensitivity is less than $0.01 \mathrm{mg} / \mathrm{m}^{3}$; Alarm sys- 
tem setting feature; Battery: Ni-Cad rechargeable battery; Continuous operating time is more than 8 hours; Battery charging time is from 10 12 hours; Output signal (analogue): 0 2V; Operating conditions: Humidity is less than $95 \%$ (without steam condensation); Dimension: $9 \times 3 \times 1.5$.

- Weight: $0.9 \mathrm{~kg}$

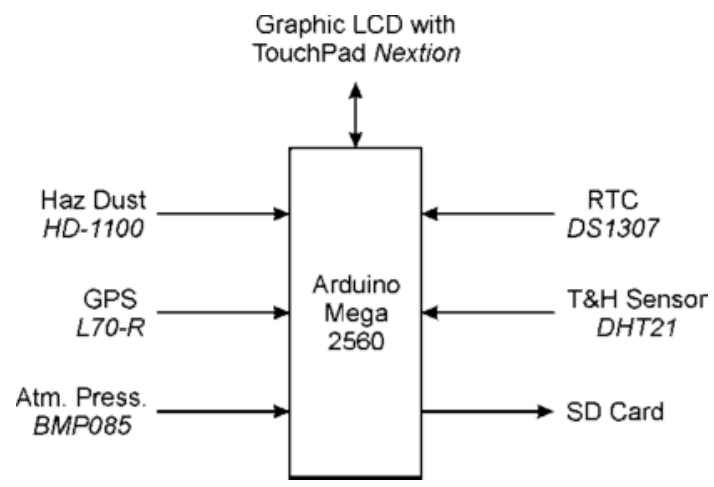

Fig. 1. The general principle diagram of mobile dust monitoring device

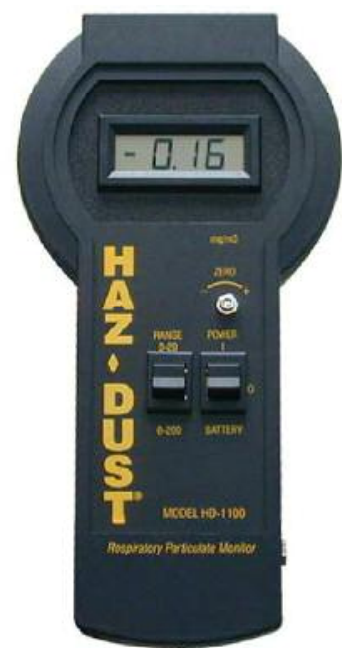

Fig. 2. The dust measuring device HD-1100

\section{(2) Central processor unit}

This paper selected the Arduino Mega 2560 as the main microcontroller board. The board is based on the ATmega2560. It has 54 digital input/output pins (of which 15 can be used as PWM outputs), 16 analog inputs, 4 UARTs (hardware serial ports), a $16 \mathrm{MHz}$ crystal oscillator, a USB connection, a power jack, an ICSP header, and a reset button (https://www.arduino.cc/en/Guide/).

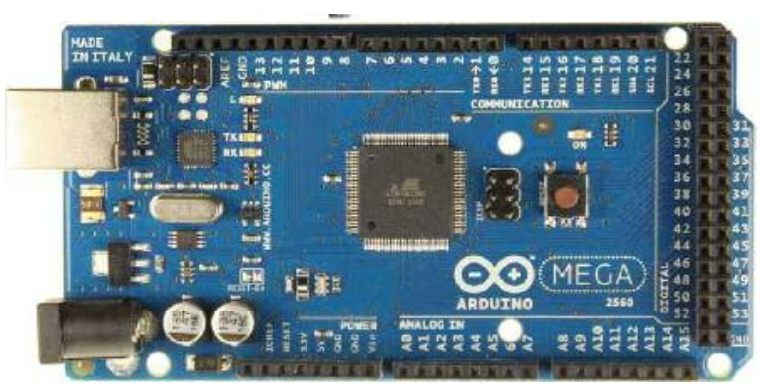

Fig. 3. The Arduino Mega 2560 Board

\section{(3) Display screen}

The graphical LCD screen Nextion NX4832K035 was selected in order to increase the display capability. It has also a built-in touchpad to interact with the user so that we do not need to provide an additional keypad for inputting commands (https://nextion.tech/).

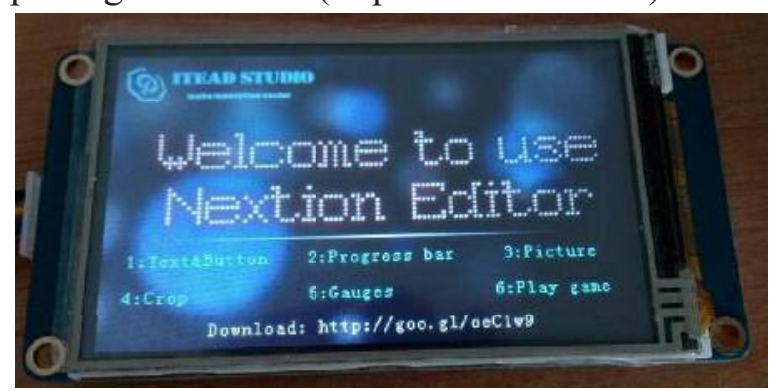

Fig. 4. The GLCD with TouchPad from Nextion

(4) Memory card

A flash memory card with capacity around 4GB is sufficient for general purposes of this device (Youngblood, 2015). It could be used to continuously record and store data for a period of 12 months.
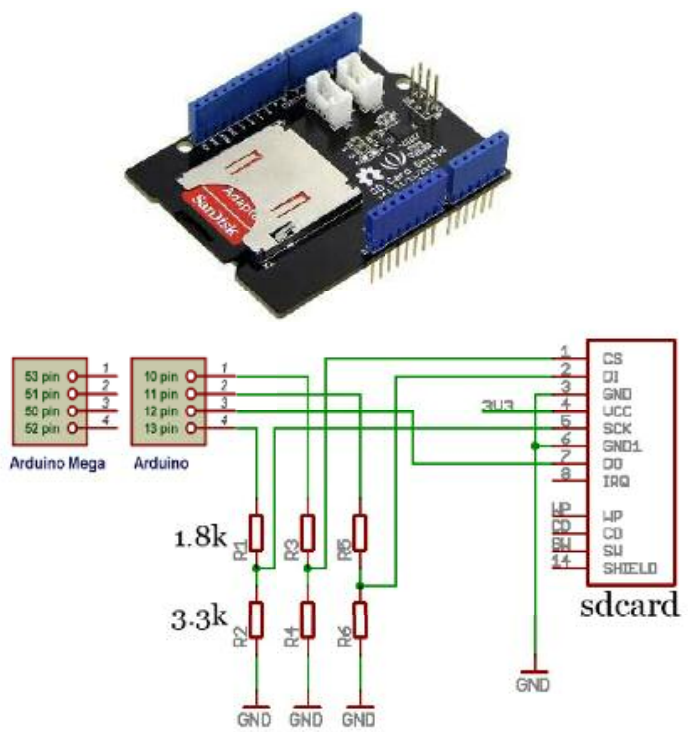

Fig. 5. The SD card and its connection with Arduino Mega 2560 Board 
(5) GPS navigation

GPS L70-R: For GPS location of the measuring points, we use the very popular IC L70-R from Quectel (https://www.quectel.com/).
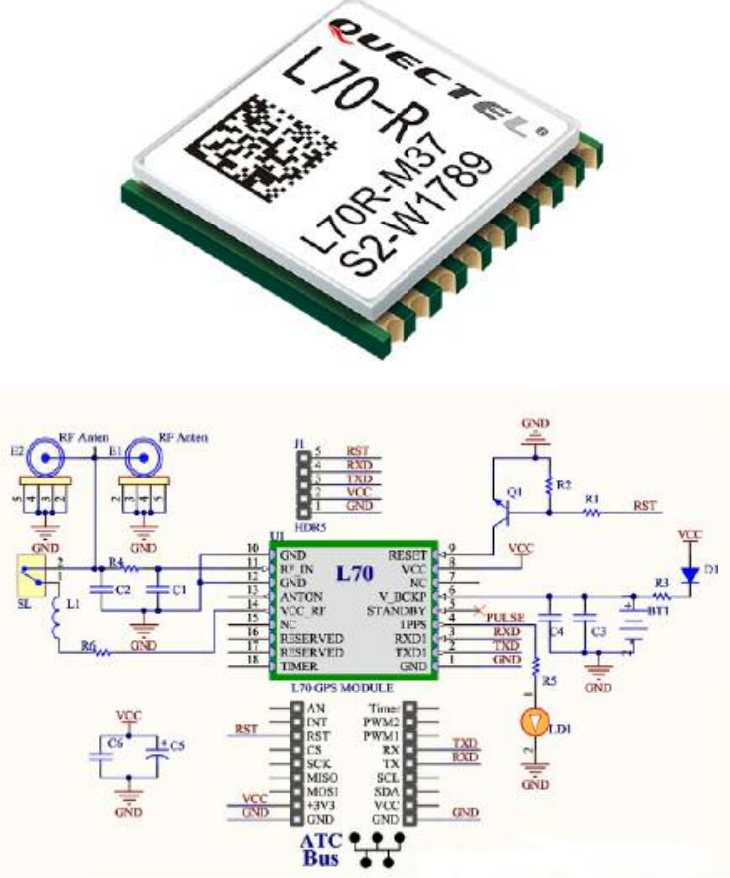

Fig. 6. The GPS L70-R and its connection schematic

(6) Pressure sensor

BMP085: To measure the atmospheric pressure, we use the sensor BMP085 made by Bosch as shown in following figure (http://wiring.org.co/learning/libraries/).
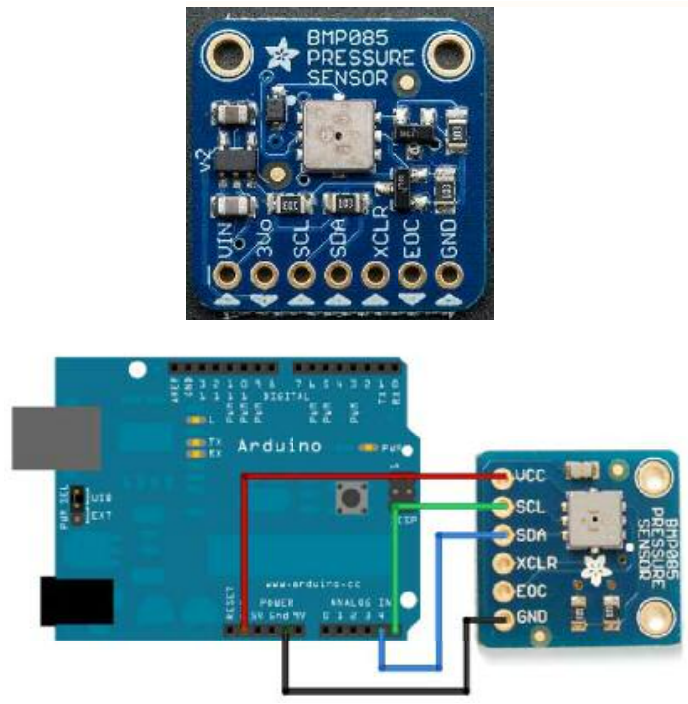

Fig. 7. The atmospheric pressure sensor BMP085 and its schematic connection with Arduino Mega 2560
(7) Temperature and humidity sensor

DHT21: In this paper, this study uses the DHT21/AM2301 temperature and relative sensor from AOSONG (Aosong Electronics Co., Ltd.). The specifications as below: Power supply: 1.8 - 3.6V; Power consumption: $0.5 \mathrm{uA}$ at 1Hz; Communication: I2C standard; I2C Speed max: 3.5MHz; Noise level: $0.02 \mathrm{hPa}(17 \mathrm{~cm})$; Measuring range: $300 \mathrm{hPa} \sim 1100 \mathrm{hPa}(9000 \mathrm{~m}$ to $-500 \mathrm{~m}$ ); Response time: $7.5 \mathrm{~ms}$; Weight: $1.18 \mathrm{~g}$; Size: $21 \mathrm{~mm}$ x $18 \mathrm{~mm}$; Operating temperature: 40 to $85^{\circ} \mathrm{C}$.
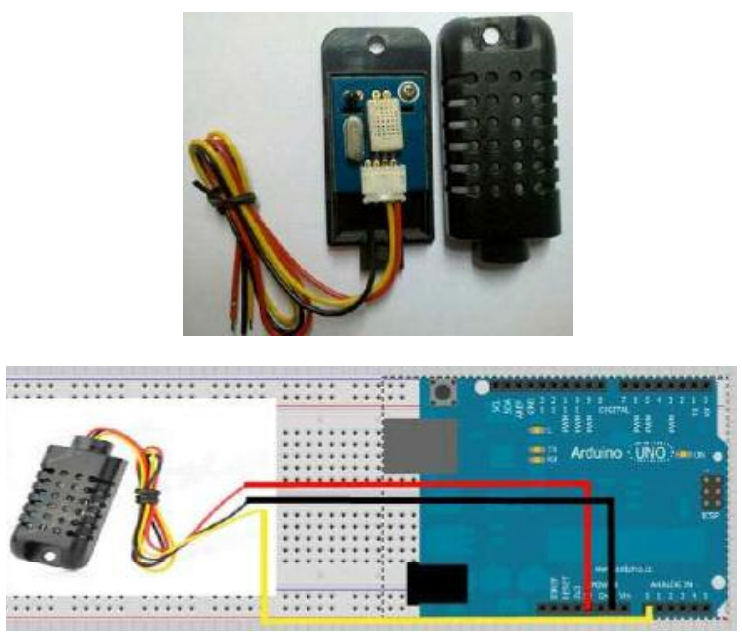

Fig. 8. The atmospheric pressure sensor BMP085 and its connection schematic with Arduino Board

(8) IC timer

DS1307: To have correct time of the measurements, the device uses a RTC (Real Time Clock) IC DS1307.
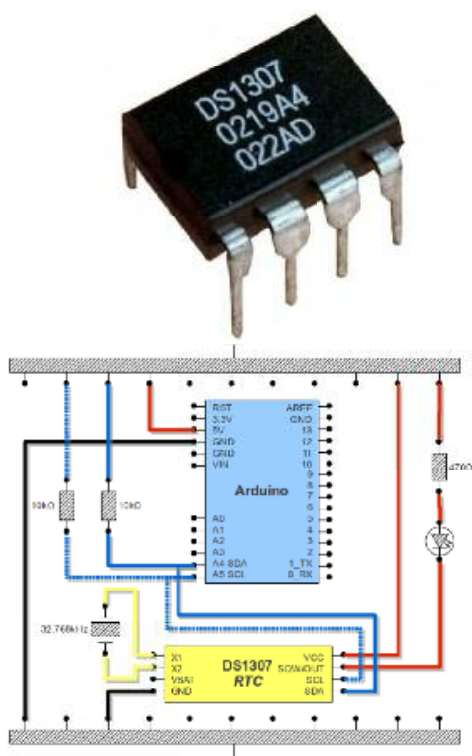

Fig. 9. The RTC DS1307 and its connection schematic with Arduino Board 
(9) The results of design and installation

The device is powered by $5 \mathrm{~V}$ battery. The above designs and descriptions was fully implemented and successfully tested. The resulted device is very light and compact (with the dimensions of $12 \mathrm{~cm} \times 7 \mathrm{~cm} \times 4 \mathrm{~cm})$. The main board of the device is shown in the Fig. 10.

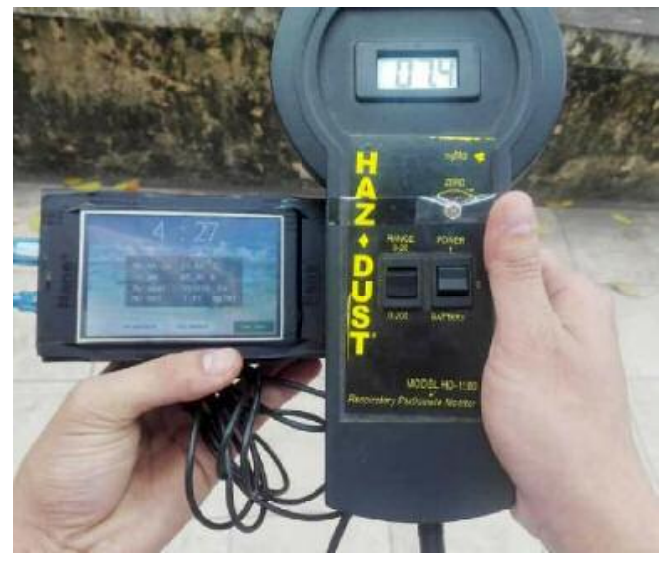

Fig. 10. The designed product

The tests have confirmed all the design requirements are fulfilled; all the signals are collected successfully and correctly. The data can be easily copy into the PC since the file is in FAT32 format. The monitoring data from the mobile device is in the excel file format with parameters namely ID, time, date, temperature, humidity, pressure, dust concentration, longitude and latitude. The data is continuously recorded after each step within 5 seconds.

\section{(10) The equipment calibration}

To ensure the accuracy of monitoring data, the mobile dust measuring device has been calibrated and certified by the Vietnam Metrology Institute (the registration number of DK 05).

\subsection{Mobile dust monitoring}

The scope of monitoring was the traffic roads (La Thanh, Lang Ha, Ring Road No. 3, Tran Duy Hung, Nguyen Chi Thanh) in the urban districts of Hanoi City. The monitoring time period was the implementation of mobile TSP dust monitoring has been conducted from December 26, 2018 to January 5, 2019 with two time frames as peak hour (from 6 to 9 hours and from 17:00 to 20:00), and off-peak hour (the remaining time frames)

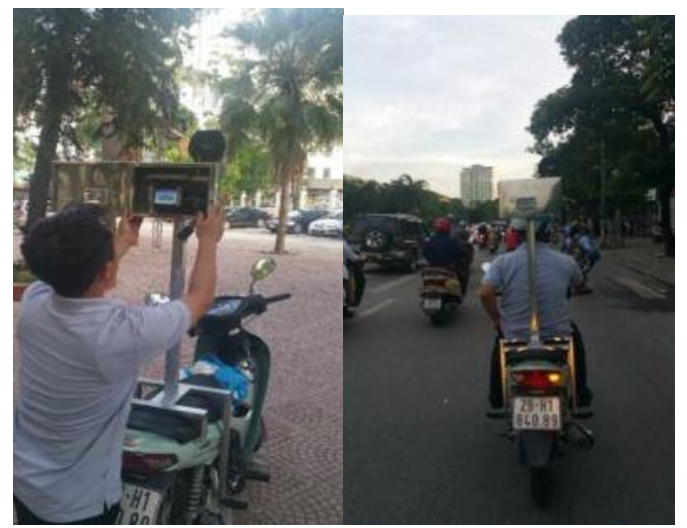

Fig. 11. Mobile dust monitoring by motorcycles

The monitoring data from the mobile device was added to the excel file format with parameters namely ID, time, date, temperature, humidity, pressure, dust concentration, longitude and latitude. The data were continuously recorded after each step within 5 seconds.

Thereafter, the ArcGIS software (the latest version of ArcGIS 10) has been utilized to develop dust pollution maps for the monitoring routes.

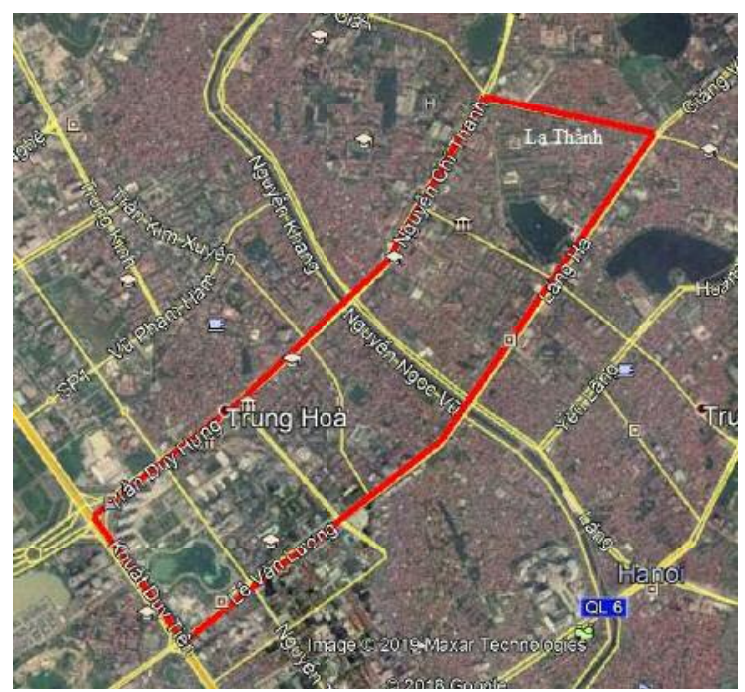

Fig. 12. The monitoring route: La Thanh Lang Ha - Le Van Luong - surrounding Road No.3 (Khuat Duy Tien) - Tran Duy Hung Nguyen Chi Thanh road

\section{Results and discussions}

To evaluate the monitoring results from the 
device, the survey team conducted a parallel monitoring of Haz Dust 1100 and Met one GT521. Monitoring time was 8-9 hours on May 1, 2017. Observing route was in Nguyen Xien Street, start-point coordinates (20.97252, 105.8195), end-point coordinates (20.99149, 105.8032). The recording time of Haz Dust 1100 was 5 seconds. The recording time of Met one GT-521 device was 10 seconds. The results presented the current situation of TSP dust concentration according to peak and off-peak hours in some traffic routes in Hanoi City from mobile monitoring data.

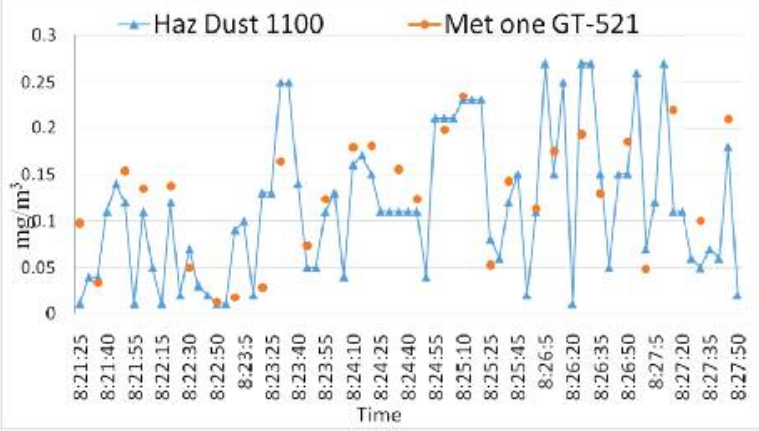

Fig. 13. The results of TSP dust concentration

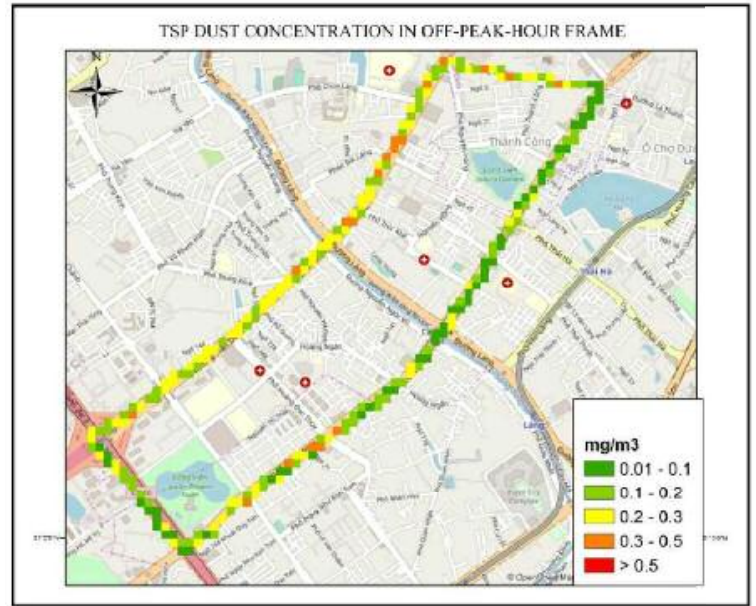

Fig. 14. The TSP dust concentration during offpeak hours at some traffic routes

The TSP dust concentration on traffic routes depended upon the density of vehicles, the amount of dust on roadbeds and surrounding construction activities. It was seen that even in off-peak hours, the TSP dust concentration was also fairly high on the route of La Thanh, Tran Duy Hung and Nguyen Chi Thanh. The moni- tored value was from $0.2-0.3 \mathrm{mg} / \mathrm{m}^{3}$. Furthermore, many monitoring locations such as Nguyen Chi Thanh - La Thanh crossroad, Nguyen Chi Thanh - Chua Lang crossroad have been monitoring value of $0.3-0.5 \mathrm{mg} / \mathrm{m}^{3}$ that exceeded the National Technical Regulation 05:2013/BTNMT (average 1 hour).

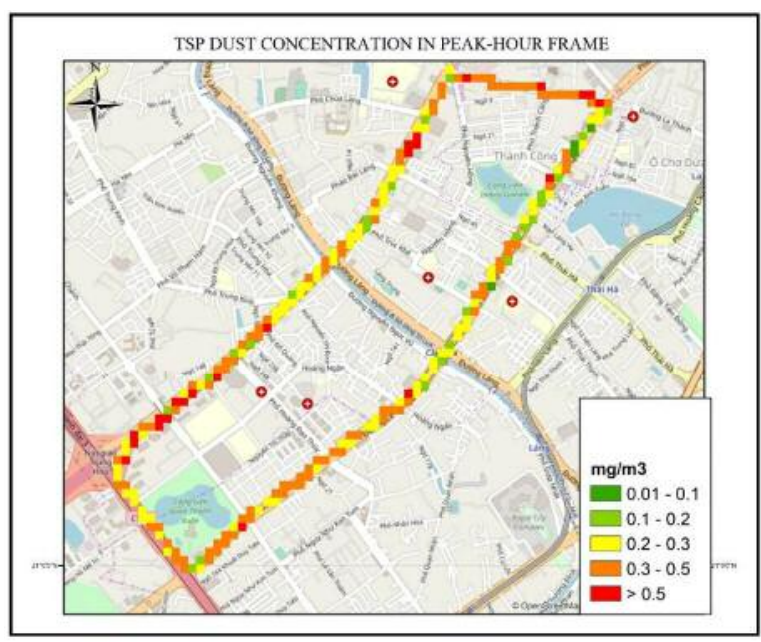

Fig. 15. The TSP dust concentration during offpeak hours at some traffic routes

The Fig.15 indicates the concentration of TSP dust during off-peak hours in La Thanh, Lang Ha, Le Van Luong, Khuat Duy Tien, Tran Duy Hung and Nguyen Chi Thanh road. The dust level during off-peak hours was much higher than off-peak hours (from 1.2 to 1.5 times). Additionally, most of the monitoring positions exceeded the permissible standard. The areas of high TSP dust concentration consisted of $\mathrm{La}$ Thanh street, Nguyen Chi Thanh - Lang intersection and Lang Ha - Lang intersection. The observed value ranged from 0.5 to $0.6 \mathrm{mg} / \mathrm{m}^{3}$ and exceeded the permitted value by $1.5-2$ times.

Through the monitoring results, it could be noticed that dust pollution sources on the inner roads mainly come from the rolling dust from road surface and transportation.

The mobile dust monitoring equipment was designed and assembled on some main roads of Hanoi city. In the process of monitoring, the research team has found that the device has some advantages and disadvantages as follows: 1) It is a mobile monitoring device which easily in- 
stalled on traffic vehicles such as electric bicycles, motorcycles, cars, etc; 2) The sensor head has a firm structure; 3) Many parameters including as measurement time, dust concentration, temperature, humidity, pressure and location (GPS) could be monitored; 4) The display unit (LCD screen) has a small size, compact; and could display many types of data at the same time; 5) The equipment operates continuously and stably; 6) The equipment is easy to use and operate; 7) The device automatically records data after a period of 5 seconds and could store statistic for long periods (about 12 months); 8) The device records data as a .csv file (compatible with excel), therefore, it is easy to extract and process data; 9) It is the suitable monitoring equipment for electric bicycles or motorcycles; 10) The device could easily replaces the sensors once a problem or failure occurs; 11) Sensors are supplied by reputable manufacturers, it is therefore easily obtained in case of requiring replacement; 12) It has competitive price compared to mobile monitoring systems with the same function.

Besides, there are some disadvantages in this equipment such as: 1) The device only indirectly monitors TSP dust, and the PM10 dust could be observed through the percentage of TSP dust; 2) The threshold dust concentration (or allowed monitoring limits) of the device: $0.01 \mathrm{mg} / \mathrm{m} 3 ; 3$ ) The device could not be utilized in rainy conditions; 4) The monitoring results are written directly to memory cards, the device has no online data port; 5) The data shows error when moving in complex terrains that leads to fluctuations in vehicles (electric bicycles, motorcycles, cars, etc.) installed the mobile dust monitoring equipment; 6) The device does not monitor the wind speed and wind direction; whereas, wind parameters considered as the main factors, directly affect the monitoring results of dust concentration on traffic routes.

\section{Conclusion}

The study has presented about the design of a portable dust measurement device. By using pro- grammable Arduino board, the device is compact, accurate and well-connected with the Haz Dust device as expected. The further upgrades may include as wireless connection between the device and the host computer, or other environmental parameters to be measured.

The device has been applied for mobile dust monitoring in some main streets of Hanoi city. The observation process has shown that the device operates stably with high accuracy.

\section{References}

1. Adams, M.D., DeLuca, P.F., Corr, D., Kanaroglou, P.S., 2012. Mobile air monitoring: Measuring change in air quality in the city of Hamilton, 2005-2010. Social Indicators Research, 108: 351-364.

2. Airparif, 2009. Influence des amenagements de voirie sur l'exposition des cyclists a la pollution atmospherique; Study report Airparif: Paris, France.

3. Aosong Electronics Co., Ltd. Temperature and humidity moduleAM2301Product Manual, https://kropochev.com/downloads/humidity/AM 2301.pdf

4. Devarakonda, S., 2013. Real-time Air quality monitoring through mobile sensinh in metropolitan areas.

5. Dionisio, K.L., Rooney, M.S., Arku, R.E., Friedman, A.B., Allison, F.H., Vallarino, J., Agyei-Mensah, S., Spengler, J.D., Ezzati, M., 2010. Within-neighborhood patterns and sources of particle pollution: Mobile monitoring and geographic information system analysis in four communities in Accra, Ghana. Environmental Health Perspectives, 118: 607-613.

6. Dons, E., Int Panis, L., van Poppel, M., Theunis, J., Willems, H., Rudi, T., Wets, G., 2011. Impact of time-activity patterns on personal exposure to black carbon. Atmospheric Environment, 45: 3594-3602.

7. Kaur, S., Nieuwenhuijsen, M.J., Colvile, R.N., 2007. Fine particulate matter and carbon monoxide exposure concentrations in urban street transport microenvironments. Atmospheric Environment, 41: 4781-4810. 
8. Isakov, V., Touma, J.S., Khlystov, A., 2007. A method for assessing air toxics concentrations in urban areas using mobile platform measurements. Journal of the Air \& Waste Management Association, 57: 1286-1295.

9. Mead, M.I., Popola, O.A.M., Stewat, G.B., Landshoff, P., Calleja, M., Hayes, M., 2012. The use of electrochemical sensors for monitoring urban air quality in low-cost, high-density networks.

10. Vogel, A., Weber, K., Fischer, C., Van Haren, G., Pohl, T., Schneider, F., Pesch, M., 2011. Innovative optical particle spectrometer to monitor spatial and temporal fine dust and ultra fine particles in low emission zones in Düsseldorf. In Proceedings of Poster Presentation at the PMx and UFP Monitoring Workshop of the Euregional PM-Lab Project at ISSeP, Liege, Belgium, 8-9 December 2011.

11. Wallace, J., Corr, D., DeLuca, P., Kanaroglou, P., McCarry, B., 2009. Mobile monitoring of air pollution in cities: The case of
Hamilton, Ontario, Canada. Journal of Environmental Monitoring, 11: 998-1003.

12. Youngblood, T., 2015. Reading and Writing Files from an SD Card with an Arduino, https://www.allaboutcircuits.com/projects/reading-and-writing-files-from-an-sd-card-with-anarduino/.

13. Yu, X., Zhang, W., Zhang, L., Li, V.O.K., Yuan, J., You, I., 2013. Understanding urban dynamics based on pervasive sensing: An experimental study on traffic density and air pollution, Mathematical and Computer Modelling 58: 1328-1339.

14. https://www.skcinc.com/catalog/pdf/instructions/HD-1100\%20Instruction\%20Manual.pdf

15.https://www.arduino.cc/en/Guide/ArduinoMega2560.

16. https://nextion.tech/

17.https://www.quectel.com/UploadFile/Prod uct/

18. http://wiring.org.co/learning/libraries/ 